\title{
Projeto de ensino de História do Cepae: itinerários para a prática PEDAGógica
}

\author{
Andréa Ferreira Delgado* \\ Mônica Martins da Silva** \\ Segismunda Sampaio da Silva Neta***
}

\section{ResUMO}

Este texto trata da proposta teórico-metodológica de ensino de História do Centro de Ensino e Pesquisa Aplicada à Educação (Cepae) da Universidade Federal de Goiás, criada entre os anos de 2003 e 2004 e ainda em vigor, e fundamenta-se em reflexóes teóricas acerca da história e em discussóes a respeito do processo de ensino-aprendizagem, mais precisamente da construção do saber histórico no espaço escolar. Aborda-se a trajetória de reflexóes e discussóes que culminaram com a criação de eixos comuns que possibilitaram a unificação do trabalho pedagógico das séries iniciais e finais do Ensino Fundamental e Médio, bem como da proposta de ensino de História que orienta o trabalho pedagógico, a partir da qual são construídos os planos de ensino para cada uma das séries. Pretende-se explicitar os procedimentos e objetivos que configuram determinada concepção de ensinoaprendizagem dessa disciplina escolar, incorporando as modificaçôes que resultam das discussóes sistemáticas realizadas ao longo desses anos pelos professores da Subárea de História do Cepae.

Palavras-chave: ensino de História, saber histórico escolar, prática pedagógica.

\section{Cepae's history teaching project: itineraries for pedagogical practice}

\section{Abstract}

This text refers to Cepae's (Federal University of Goiás' Center of Teaching and Applied Research for Education) theoretical and methodological proposal of History Teaching, created between the years of 2003 and 2004. The mentioned proposal, still in use, is based on theoretical reflexions over History as well as in discussions about the teaching and learning process, more precisely about the construction of historical knowledge taken at school. There's an approach here on the trajectory of reflexions and discussions which resulted in the creation of common axes that made possible the unification of the pedagogical work

Professora da Subárea de História do Cepae/UFG de 1994 a 2008. Atualmente é professora do Departamento de Metodologia do Ensino da Universidade Federal de Santa Catarina. E-mail: andreadelgado@uol.com.br

** Professora de História do Cepae/UFG. E-mail: moniclio@uol.com.br

** Professora de História do Cepae/UFG: E-mail: segis1717@hotmail.com 


\section{Revista Solta a Voz, v. 20, n. 2}

done at the first and the last grades of elementary school and secondary school. The proposal of History teaching is also mentioned. Such proposal, which guides the pedagogical work, is the source from where the teaching plans are made, for every school grade. This article also aims to make explicit the procedures and objectives that set up a particular History teaching and learning conception, which incorporates the transformations resulted from systematic discussions done during these last years by Cepae's teachers of the sub-area of History.

KeY wORDS: History teaching, school historical knowledge, pedagogical practice.

\section{INTRODUÇÃ́O}

A proposta de ensino da Subárea de História do Centro de Ensino e Pesquisa Aplicada à Educação (Cepae) fundamenta-se em reflexôes teóricometodológicas acerca da História e do processo de ensino-aprendizagem, mais especificamente da construção do conhecimento histórico escolar, e tem como objetivo estabelecer os eixos para o trabalho pedagógico no Ensino Fundamental e Médio, a partir dos quais professores e professoras elaboram os Planos de Ensino para cada uma das séries.

O processo de elaboração dessa proposta ocorreu em 2003 e 2004, de forma simultânea à efetivaçáo de uma nova forma de organização do trabalho pedagógico no Cepae, que reuniu pedagogos e professores com licenciaturas específicas em subáreas, a fim de discutir e planejar o ensino a partir do estudo de cada disciplina. Sob a coordenaçáo da professora Andréa Ferreira Delgado, a sistematização da proposta foi o resultado de uma série de reunióes realizadas a partir de uma metodologia de discussóes que tinha como objetivo relacionar o estudo dos aspectos teóricos e metodológicos do ensino de História com a reflexão dos problemas enfrentados no planejamento e no cotidiano da sala de aula.

Desde então, o documento Projeto de Ensino da Subárea de História (Cepae, 2004) fundamenta a prática pedagógica do primeiro ano do Ensino Fundamental ao terceiro ano do Ensino Médio, constituindo também um instrumento importante para o trabalho desenvolvido na orientaçáo dos(as) estagiários(as) do curso de História da UFG. Além da fundamentação teórica e metodológica, que é o objeto deste artigo, o documento apresenta consideraçóes sobre os anos iniciais e finais do Ensino Fundamental e acerca do Ensino Médio, explicitando a organização curricular por meio da ementa, dos objetivos, dos conteúdos e da bibliografia de cada uma das séries. 
Neste artigo, mais do que a problematização teórica, pretende-se explicitar os procedimentos e objetivos que configuram determinada concepção de ensino-aprendizagem dessa disciplina escolar, incorporando as modificaçóes que resultam das discussões sistemáticas que realizamos ao longo desses anos. Desejamos, assim, compartilhar a experiência de trabalho da subárea de História do Cepae.

\section{O CONHECIMENTO HISTÓRICO ESCOLAR: A HISTÓRIA COMO DISCIPLINA ESCOLAR}

Um dos fundamentos do Projeto de Ensino da Subárea de História é a compreensão de que a história escolar deve trabalhar com conceitos, conteúdos e procedimentos da História, ou seja, constitutivos do campo da produção do conhecimento histórico. No momento da elaboração da proposta, utilizávamos a categoria "transposiçáo didática" para enfatizar que o ensino-aprendizagem de História deveria se configurar a partir do discurso histórico, numa acepção semelhante à de Schimidt e Cainelli (2004, p. 32):

Busca-se a realizaçáo, na sala de aula, da atividade do historiador, a articulação dos elementos constitutivos do saber histórico com os do fazer pedagógico. Assim, o objetivo é fazer o conhecimento histórico ser ensinado de tal forma que dê ao aluno condiçôes de participar do processo do fazer, do contar e do narrar a história.

A transposição didática, na acepção estabelecida por Yves Chevallard, faz referência "à passagem do saber acadêmico ao saber ensinado e, portanto à distância eventual, obrigatória que os separa" (Chevallard, 2005, p. 16) e nos auxiliou a estabelecer a diferença conceitual entre o saber acadêmico e o saber escolar, para delinear um campo próprio à prática de ensino do professor.

Ao longo desses anos, estabelecemos interlocução com um conjunto de autores (Chervel, 1990; Forquin, 1993; Lopes, 1997a, 1997b; Monteiro, 2005a, 2005b, 2007), que, a partir de diferentes abordagens, investigam o processo de escolarização dos saberes e promovem um diálogo crítico com Chevallard. Interessa-nos, portanto, explicitar essa trajetória, mostrando nossa leitura da contribuição desse autor e dos motivos que nos levam a preferir utilizar a categoria "saber histórico escolar" para delinear as especificidades do objeto do nosso fazer pedagógico. 
Trabalhando com exemplos advindos da matemática, Chevallard identifica três níveis distintos de saberes: o "saber sábio", ou, na tradução brasileira mais utilizada, "saber acadêmico", aquele produzido pelas instituiçóes e agentes autorizados a realizar a pesquisa científica; o "saber a ensinar", que está presente nos currículos e livros utilizados, e o "saber ensinado", aquele efetivamente ensinado em sala de aula. De acordo com o autor, a transposição didática torna-se necessária "porque o funcionamento didático do saber é distinto do funcionamento acadêmico, porque há dois regimes de saber, inter-relacionados, mas não sobrepostos" (Chevallard, 2005, p. 25, tradução nossa). Ao advogar essa especificidade, a análise concentra-se no trabalho de "transposição didática", quando, a partir do saber acadêmico, entra em cena um conjunto de procedimentos de seleção e estruturação didática responsável pela produção do saber a ensinar e do saber ensinado.

Para Chevallard (2005, p. 28-29), a definição dos saberes a ensinar a partir do saber acadêmico, ou seja, a transposição didática lato sensu ocorre na "noosfera", onde "os representantes do sistema de ensino, com ou sem mandato, se encontram, direta ou indiretamente, com os representantes da sociedade (os pais dos alunos, os especialistas da disciplina que militam em torno do seu ensino, os emissários dos órgãos políticos)". Já a transposição didática stricto sensu - a transformação de um conteúdo de saber a ensinar em uma versão didática desse objeto de saber - ocorre no interior do "sistema didático", ou seja, nas relaçóes entre o professor, o aluno e o saber. Por isso, o autor ressalta que a transposição didática inicia muito antes da intervenção direta dos professores, que, ao realizarem o trabalho de didatização, transformam o saber a ser ensinado, configurado no "currículo formal”, na definição advinda do campo do currículo (Moreira; Silva, 1995; Moreira, 2003), em saber ensinado no "currículo em ação" na sala de aula.

Chevallard, portanto, ao elaborar a noção de transposição didática, traz importante contribuição teórica para fundamentar a diferenciação entre os saberes e a consolidação do saber agenciado na escola como um campo próprio do conhecimento. Operando com os conceitos desse autor como um dos pressupostos da nossa proposta de ensino, afirmamos que o saber a ensinar e o saber ensinado são irredutíveis ao saber acadêmico e que devemos estar atentos aos procedimentos de construção didática dos saberes, ou seja, ao conjunto de instituiçóes, agentes e interesses que determinam o que deve ser ensinado, como deve ser ensinado e, finalmente, o que é efetivamente ensinado em sala de aula. 
Entretanto, também acompanhamos as discussóes suscitadas a partir desse modelo proposto por Chevallard, tanto no campo da sociologia do currículo como no campo do ensino de História, buscando incorporar outras contribuiçóes que auxiliassem na problematização do "saber escolar enquanto forma de saber específico de natureza seletiva e com um certo grau de autonomia epistemológica" (Gabriel, 2000, p. 239).

Os críticos apontam como limitação o fato de Chevallard considerar o saber acadêmico como a única referência/fonte para a constituição e as transformações do saber ensinado. Se considerarmos que esse autor enfatiza a distinção entre os saberes, o próprio termo "transposição didática" termina por destacar aquilo que pretende questionar: a equivalência entre saber escolar e saber acadêmico. Afinal, se os saberes são distintos, como nos ensina o próprio Chevallard, não se trata de transpor ou transferir o conhecimento produzido nas instituiçóes acadêmicas para o interior da escola por meio de operaçóes didáticas. Monteiro (2007, p. 87-88) sintetiza bem essas críticas:

Chevallard não considera em sua análise, de forma explícita, a dimensão educativa que, em minha perspectiva, é um elemento epistemológico estruturante, fundamental para que se possa compreender o processo de constituição do saber escolar. O contexto sociopolítico cultural configura um quadro dentro do qual opçóes são realizadas para a definiçáo dos saberes a ensinar e ensinado e, também, inclusive para a definiçáo e orientaçấo das diferentes linhas de pesquisa que dão origem ao saber acadêmico. Ao se referir às demandas do entorno ou ao desgaste do saber ensinado em face das inovaçôes, mudanças e demandas sociais, ele nos remete ao saber acadêmico para corrigi-las e atualizá-lo. Percebe-se um posicionamento que busca manter a análise e seus referenciais dentro de um enquadramento científico e que encontra dificuldades para reconhecer o enraizamento sociopolítico-cultural da construção dos saberes acadêmicos e escolares.

No entanto, no trabalho citado e em outros quatro, Monteiro (2001; 2003; 2005a; 2005b) ressalta a importância da contribuição de Chevallard e destaca seu "potencial instigante que, aliado à contribuição de outros autores, pode fornecer um instrumental para a melhor compreensão dos processos de ensino, considerando as especificidades das diferentes disciplinas” (Monteiro, 2003, p. 16). 
Ao abordar o conhecimento escolar, Circe Bittencourt (2004) contrapóe a concepção de "transposição didática" construída por Chevallard à categoria "disciplina escolar", concebida como campo de conhecimento autônomo. Sem discutir suficientemente as proposiçóes de Chevallard, a autora constrói uma interpretaçáo muito negativa ao afirmar que "essa abordagem considera a disciplina escolar dependente do conhecimento erudito ou científico" e resulta na compreensão da "existência de uma hierarquia de conhecimentos, encontrando-se a disciplina escolar em uma escala inferior, como saber de segunda classe, legitimado pelo saber científico" (Bittencourt, 2004, p. 36).

Como contraponto, Bittencourt filia-se ao campo denominado "história das disciplinas escolares", tal como delineado por André Chervel (1990), para defender um estatuto específico e autônomo para as disciplinas escolares, destacando o papel exercido pela escola e pela cultura escolar na produção de um saber próprio.

Em decorrência da concepção de escola como lugar de produção de conhecimento, as disciplinas escolares devem ser analisadas como parte integrante da cultura escolar, para que se possam entender as relaçóes estabelecidas com o exterior, com a cultura geral da sociedade. [...] A seleçáo de conteúdos escolares, por conseguinte, depende essencialmente de finalidades específicas e assim não decorre apenas dos objetivos das ciências de referência, mas de um complexo sistema de valores e de interesses próprios da escola e do papel por ela desempenhado na sociedade letrada e moderna. (Bittencourt, 2004, p. 39)

Não concordamos com essa contraposição simplista entre a noção de transposição didática e as contribuiçôes dos teóricos que estudam as disciplinas escolares. Ao contrário, compartilhamos a ideia de outros especialistas no campo de ensino da História que buscam investigar as proposiçóes de um conjunto diversificado de autores, estudando profundamente cada uma das perspectivas de análise do conhecimento escolar. Por isso, desejamos explorar um pouco mais as possibilidades de compreensão da História ensinada a partir da produção do campo da história das disciplinas escolares.

O francês André Chervel, em artigo seminal para esse campo da pesquisa educacional, historiciza o próprio conceito de "disciplina escolar". O autor destaca que, na acepção atual do termo, "os conteúdos de ensino 
são concebidos como entidades sui generis, próprios da classe escolar, independentes, numa certa medida, de toda realidade cultural exterior à escola" (Chervel,1990, p. 180), visto que sua organização, funcionamento e eficácia são explicados a partir da própria história das disciplinas escolares.

A partir dessa concepção, esse autor constrói uma crítica contundente à noção de que na escola são ensinadas as ciências de referência - termo com o qual ele designa o conhecimento produzido nas instituiçóes acadêmicas - e que a tarefa do professor consiste em operar com os métodos, com objetivo de "que os alunos assimilem o mais rápido e o melhor possível a maior porção possível da ciência de referência” (Chervel, 1990, p. 181).

Em contrapartida, renegando a compreensão dos conteúdos de ensino como vulgarizaçóes ou adaptaçóes das ciências de referência, Chervel elabora uma concepção da história das disciplinas escolares que coloca três ordens de problemas a serem considerados pelo pesquisador interessado no estudo da constituição e funcionamento de cada disciplina:

O primeiro é o de sua gênese [gênese da disciplina escolar]. Como a escola [...] começa a agir para produzi-la? O segundo refere-se à sua função. [...] Já que ela ensina suas próprias produçôes, não se pode senão se questionar sobre suas finalidades: elas servem para quê? Por que a escola foi levada a tomar tais iniciativas? Em quê determinada disciplina responde à expectativa dos pais, dos poderes públicos, dos que decidem? Terceiro e último problema, o de seu funcionamento. [...] Questão: como as disciplinas funcionam? De que maneira elas realizam, sobre o espírito dos alunos, a "formação" desejada? Que eficácia real e concreta se lhes pode reconhecer? Ou, mais simplesmente, quais são os resultados do ensino? (Chervel, 1990, p. 183-184)

Questóes como essas nos ajudam a delinear a complexa problemática da produção, função e funcionamento da história como disciplina escolar, que abrange desde os mecanismos de constituição dos saberes escolares até as práticas docentes em sala de aula.

Na elaboração de uma proposta de ensino de História, partimos do pressuposto de que a experiência docente na educação básica desempenha função significativa no processo de construção do conhecimento escolar que ora problematizamos. Por isso, entre tantos aspectos até aqui discutidos, interessa-nos destacar o papel dos docentes na transposição didática e no processo de construção das disciplinas escolares. Para tanto, continuaremos a problematizar a relação entre o conhecimento escolar e o saber 


\section{Revista Solta a Voz, v. 20, n. 2}

acadêmico, como denomina Chevallard, ou o saber de referência, como prefere Chervel, a partir da perspectiva da prática docente.

Nesta reflexão, ressaltamos a contribuição de Alice Ribeiro Casimiro Lopes, que propõe a noção de "mediação didática" para a compreensão do trabalho de (re)construção de saberes promovido pelos professores que didatizam o conhecimento científico de forma necessariamente articulada com as experiências e os conhecimentos cotidianos dos alunos. Nas palavras da autora:

Prefiro referir-me a um processo de mediação didática, todavia não no sentido genérico conferido à mediação: ação de relacionar duas ou mais coisas, de servir de intermediário ou de ponte, de permitir a passagem de uma coisa a outra. Utilizo o termo mediação em seu sentido dialético: um processo de constituição de uma prática realizada através de mediaçóes contraditórias, de relaçóes complexas, não imediatas, com um profundo senso de dialogia. (Lopes, 1997b, p. 106)

São essas relaçóes complexas entre os saberes que constituem o conhecimento escolar com configuraçóes cognitivas próprias. "As disciplinas escolares reorganizam o conhecimento científico em novas subdivisões, que não necessariamente correspondem às divisóes dos saberes acadêmicos e/ou científicos" (Lopes, 1997a, p. 52). Nesse processo de disciplinarização, o objetivo das instituiçóes escolares é tornar o conhecimento do saber de referência acessível à compreensão dos alunos. Não se trata, no entanto, de simples transmissão. Segundo Lopes, a mediação didática realizada no ensino-aprendizagem implica a (re)construção do conhecimento científico e do conhecimento cotidiano, de forma a produzir um saber epistemologicamente diferente: o conhecimento escolar.

Nesse processo de mediação didática, o professor é ator fundamental, pois é ele o responsável por didatizar o saber de referência, operando tanto com o conhecimento histórico quanto com o conhecimento pedagógico para, na interação com os alunos e suas experiências sociais, produzir o conhecimento escolar.

Em contraposição ao paradigma da racionalidade técnica, que percebia o professor como agente transmissor do conhecimento científico, o uso da categoria "conhecimento histórico escolar" evidencia o trabalho docente de produção do saber escolar, transferindo o foco de análise para a complexidade da educação escolar. 
Dessa forma, operamos com a concepção de saber escolar tal como exposta por Monteiro (2007, p. 14):

A categoria "saber escolar" foi utilizada aqui como aquela que designa um conhecimento com configuração cognitiva própria, relacionado mas diferente do saber científico de referência, e que é criado a partir das necessidades e injunçôes do processo educativo, envolvendo questóes relativas à transposição didática e às mediçôes entre conhecimento científico e conhecimento cotidiano, bem como às dimensôes histórica e sociocultural numa perspectiva pluralista. (Monteiro, 2007, p. 14)

Em síntese, compreendemos que a História escolar constitui um conhecimento que é específico em, pelo menos, dois sentidos: primeiro, é específico por causa do estatuto singular do conhecimento produzido para e na escola, agenciado e construído na prática docente, muito diferente da mera simplificação ou adaptação do conhecimento histórico produzido pelos historiadores nas instituições acadêmicas. Segundo, é um conhecimento específico, porque resulta tanto do processo de construção da história como disciplina escolar quanto da dinâmica cotidiana da sala de aula, visto que, em última instância, configura-se na interação entre professores(as) e alunos(as).

\section{A PRODUÇÁ́O DO CONHECIMENTO HISTÓRICO COMO OBJETO DO ENSINO DE HISTÓRIA}

Um dos eixos da prática pedagógica no Cepae é a incorporação da discussão a respeito da produção do conhecimento histórico como objeto do ensino de História. Adota-se a concepção de que os conteúdos devem ser tratados como versóes historicamente produzidas e, portanto, provisórias.

O conhecimento histórico é produzido pelo historiador no confronto entre as questóes que, a partir do presente, elabora para a compreensão do passado e as fontes históricas encontradas durante a pesquisa. Partimos, portanto, do pressuposto epistemológico de que a História não reconstitui o passado. Ao contrário, as práticas discursivas no campo da História instituem e objetivam os fatos históricos e imprimem determinada interpretação do passado. Compartilhando as palavras de Keith Jenkins (2004, p. 28), não queremos dizer 


\section{Revista Solta a Voz, v. 20, n. 2}

[...] que nós simplesmente inventamos histórias sobre o mundo ou sobre o passado, mas sim que a afirmação é muito mais forte: que o mundo e o passado sempre nos chegam como narrativas e que não podemos sair dessas narrativas para verificar se correspondem ao mundo ou ao passado reais, pois elas constituem a 'realidade'.

Ao analisar a produção do conhecimento histórico, Georges Duby enfatiza tanto a dimensão objetiva, configurada no compromisso do historiador com a interpretação dos vestígios históricos deixados pelos homens e mulheres, quanto a subjetividade presente no exercício do ofício do historiador.

A diferença entre o romancista e o historiador é que o historiador é obrigado a ter em conta um certo número de coisas que se lhe impóe; ele preocupa-se com a "veracidade", se quiser, talvez mais do que com a "realidade". Todos esses vestígios, o historiador não os pode conscientemente apagar, não pode apagar nenhum deles. E é obrigado a insinuar sua invenção, a sua parte de imaginação e de criação, no interior de um arquipélago. [...] Eu náo invento, enfim ... invento, mas preocupo-me em fundamentar a minha invenção nas mais firmes bases, em edificar a partir de vestígios rigorosamente criticados, de testemunhos que estejam tão precisos, tão exatos quanto possível. Mas é tudo. (Duby, s/d., p. 41-45)

O conhecimento histórico resulta, portanto, de um conjunto de itinerários que os historiadores percorrem para construir a trama da sua narrativa, que são determinados pela configuração de um inventário de questóes que se alteram em diferentes conjunturas históricas. Assim, a história está em permanente processo de construção, caracterizando-se pela possibilidade de elaboração de diferentes interpretaçóes a respeito dos fatos históricos e de um infinito conjunto de novos objetos e novas abordagens. Paul Veyne (1983, p. 53-54) afirma que

[...] o itinerário que o historiador escolhe para descrever o campo acontecimental pode ser livremente escolhido e todos os itinerários são igualmente legítimos (ainda que não sejam igualmente interessantes). É evidentemente impossível descrever a totalidade do devir e é preciso escolher; também não existe uma categoria particular de acontecimentos (a história política, por exemplo) que seria a História e se imporia à nossa escolha. 
O ensino de História, portanto, não deve privilegiar a história política, econômica, social ou cultural e nem se filiar exclusivamente à determinada concepção historiográfica. A complexidade da experiência humana e a avaliação de que há importantes estudos produzidos a partir de diferentes perspectivas historiográficas fundamentam o pressuposto expresso no Projeto de Ensino de História do Cepae de que o ensino da disciplina deve incorporar a renovação historiográfica, abordando uma multiplicidade de objetos históricos, de forma que possibilite ao aluno a apreensão do fazer histórico.

Esse tem sido o grande desafio, visto que a constituição da história como disciplina escolar caracterizou-se pelo tratamento dos conteúdos escolares a partir de narrativas que são apresentadas como o resgate dos fatos ocorridos no passado. Nossa compreensão epistemológica impóe a criação de estratégias metodológicas para que o aluno compreenda os procedimentos do ofício do historiador.

Com esse objetivo, alia-se a análise de diferentes interpretações dos fatos e processos em estudo ao trabalho com documentos históricos, considerado fundamental no ensino de História. Por um lado, discutem-se as fontes históricas utilizadas na produção de diferentes possibilidades de interpretação realizadas pelos historiadores. Por outro lado, considerando que o ensino-aprendizagem fundamenta-se na construção ativa do conhecimento histórico realizada pelo aluno, com a mediação do(a) professor(a), realizam-se atividades de interpretação de um conjunto diversificado de documentos históricos visuais, escritos, materiais e orais.

A decorrência central de uma aproximação epistemológica entre a seleção temática do professor e o procedimento histórico reside na particular atenção com a natureza das fontes enquanto objetos de uma produção histórica e, portanto, enquanto enunciados de sujeitos que ocupam diferentes lugares sociais e cuja produção nos remete à compreensão de relaçôes sociais em temporalidades distintas, segundo aquilo que Jacques Le Goff destacou como "documento-monumento". Além disso, tais enunciados também se apresentam para nós enquanto circunstâncias de expressão de diferentes linguagens da realidade e que, por sua vez, pressupóem diferentes processos de educação que permitam a construção da inteligibilidade sobre essas mesmas realidades. (Miranda, 2003, p. 305)

Além de contribuir para o desenvolvimento de múltiplas habilidades cognitivas, essas atividades de observação, interpretação e análise de 
fontes históricas constituem estratégias pedagógicas para a construção dos conceitos fundamentais para a compreensão do processo histórico.

A partir desses pressupostos a respeito da construçáo do conhecimento histórico, propóem-se como objetivos do ensino de História:

- estabelecer uma relação crítica com o conhecimento histórico, compreendendo-o como uma construção provisória do passado;

- identificar os sujeitos históricos e caracterizar as relaçôes sociais, culturais, políticas e econômicas nos diferentes períodos da história;

- incorporar a renovação historiográfica, trabalhando um conjunto de novos temas, novos objetos e novas abordagens;

- apresentar e contrapor versóes divergentes dos eventos e processos estudados, com o objetivo de confrontar interpretaçóes históricas e possibilitar ao aluno questionar o conhecimento histórico;

- privilegiar o trabalho com fontes históricas materiais, orais e escritas, considerando os agentes sociais e os contextos históricos envolvidos na sua produção e perpetuação;

- estimular o aluno a operar com conceitos históricos fundamentais - história, sujeito histórico, relaçóes sociais, cultura, poder, trabalho, dentre outros - e a desenvolver múltiplas habilidades cognitivas no processo de construção do conhecimento histórico escolar - observar, comparar, interpretar, analisar, investigar, argumentar, sintetizar, levantar hipóteses, etc.

\section{O ENSINO DE História E A FORMaÇÃo da CIDAdANia}

O Projeto Político-Pedagógico do Cepae aponta os objetivos da educação escolar:

A nossa proposta pretende instrumentalizar o aluno para sua participação na sociedade de forma autônoma, solidária, consciente, ativa e crítica, percebendo a dimensão humana nos aspectos científico, cultural, artístico e estético, ou seja, o que se pretende é educar integralmente o indivíduo. [...] o fenômeno educativo deve ser concebido como uma das formas de se efetivar a relação do indivíduo com o meio social, visando o desenvolvimento da personalidade com a aquisição de habilidades específicas que contribuirão para a construção da cidadania. $\mathrm{O}$ êxito das intervençôes edu- 
cacionais só será relevante na preparação dos indivíduos se estes tiverem uma compreensão consciente da sociedade e do seu compromisso social. (Cepae, 2002, p. 12-13)

De forma coerente, o documento da Subárea de História dialoga com a proposta acima explicitada quando afirma que, no contexto escolar, a disciplina História cumpre uma função importante na formaçáo da cidadania, visto que, tal como anunciado nos Parâmetros Curriculares Nacionais,

[...] o ensino de História pode favorecer a formação do estudante como cidadão, para que assuma formas de participação social, política e atitudes críticas diante da realidade atual, aprendendo a discernir os limites e as possibilidades de sua atuação, na permanência ou na transformação da realidade histórica na qual se insere. (Brasil, 1998a, p. 36)

Entretanto, simplesmente afirmar a relação entre educação e cidadania ou entre ensino de História e cidadania pode significar muito pouco em termos de estabelecer objetivos ou delinear eixos para a prática pedagógica. A trajetória da História como disciplina escolar no Brasil esteve associada à "difusão de uma idéia de nação que nega ou omite as diferenças sociais, culturais e econômicas" e muitas críticas já incidiram sobre o ensino de História que auxilia na construção de um passado único, homogêneo, "sempre harmonioso, e com um povo confiante no comando de líderes políticos capazes de conduzir a nação rumo ao progresso" (Bittencourt, 2003, p. 191). Compreendia-se, assim, a cidadania a partir do princípio da existência de uma identidade nacional, que omitia a discussão das desigualdades e exclusóes.

Outras compreensôes em torno do binômio História escolar e cidadania orientaram a elaboração das propostas curriculares produzidas no processo de redemocratização das décadas de 1980 e 1990, a partir do intenso repensar do ensino de História que marcou o contexto de luta pelo fim do regime militar, cuja característica unanimemente apontada pela historiografia (Bittencourt, 1998; Caimi, 2001; Fonseca, 2000) é a "mudança do objetivo da disciplina, que passa a ser categoricamente a preparação do cidadão para uma sociedade democrática” (Fonseca, 2003, p. 92).

Por isso, o próprio conceito de cidadania precisa ser colocado em questão e historicizado, sob pena de corrermos o risco de produzir apenas um manifesto abstrato de intençóes. Com esse objetivo, na elaboração da proposta de ensino propusemos uma problematização do conceito de 


\section{Revista Solta a Voz, v. 20, n. 2}

cidadania a partir dos Parâmetros Curriculares Nacionais: "[...] discutir a cidadania no Brasil de hoje significa apontar a necessidade de transformações das relaçóes sociais nas dimensóes econômica, política e cultural, para garantir a todos a efetivação do direito de ser cidadão" (Brasil, 1998a, p. 20). Incorpora-se, portanto, a ideia de que os direitos civis, políticos e sociais são dimensóes imprescindíveis da cidadania.

Ao historicizar essa ampliação dos direitos a partir da obra de T. $\mathrm{H}$. Marshall, José Murilo de Carvalho (2007, p. 11) reafirma

que a própria idéia de direitos, e, portanto, a própria cidadania, é um fenômeno histórico. O ponto de chegada, o ideal de cidadania plena, pode ser semelhante, pelo menos na tradição ocidental dentro da qual nos movemos. Mas os caminhos são distintos e nem sempre seguem linha reta.

Daí a necessidade de trabalhar experiências históricas concretas com os alunos, a fim de historicizar a constataçáo de que algumas dimensôes da cidadania podem estar presentes sem as outras e de que náo existe um percurso linear entre os direitos civis, políticos e sociais, visto que a noção de cidadania como combinação de liberdade, participação e igualdade para todos foi construída a partir das lutas dos grupos sociais pela conquista de direitos, e que só podem ser compreendidas a partir do estudo das trajetórias históricas das diferentes sociedades. $\mathrm{Na}$ defesa da igualdade de direitos, afirma-se a necessidade de

considerar o princípio da eqüidade, isto é, que existem diferenças (étnicas, culturais, regionais, de gênero, etárias, religiosas etc.) e desigualdades (socioeconômicas) que necessitam ser levadas em conta para que a igualdade seja efetivamente alcançada. (Brasil, 1998a, p. 21)

Essa proposta de cidadania fundamenta-se, portanto, na explicitação dos conflitos e das relaçóes de poder que engendram os valores hegemônicos, no reconhecimento das diferenças e na valorização da pluralidade cultural que caracteriza os grupos sociais que compóem a sociedade brasileira. Ressalta-se que a "sociedade atual solicita que se enfrente a heterogeneidade e que se distinga as particularidades dos grupos e das culturas, seus valores, interesses e identidades", de forma "que o reconhecimento das diferenças não fundamente relaçóes de dominação, submissão, preconceito ou desigualdade" (Brasil, 1998a, p. 35). 
Nessas formulaçóes dos Parâmetros Curriculares Nacionais, tal como analisou Marcelo Magalhães, combina-se a ideia da expansão e universalizaçáo dos direitos com a "questáo da cultura, no sentido do elogio à diferença", visto que a cidadania "passa a ser compreendida dentro da afirmação universal da diferença” (Magalhães, 2003, p. 178). O direito à diferença ou o elogio à heterogeneidade significa negar a existência de um cidadão universal e de uma identidade nacional homogênea e proclamar que o pertencimento a certos grupos sociais produz identidades múltiplas, particulares e heterogêneas.

Valoriza-se no ensino de História, portanto, a proposição permanente de relaçóes entre passado e presente, para orientar o estudo do processo histórico de forma a promover a análise da sociedade contemporânea e das experiências sociais dos alunos. Para tanto, estabelecemos eixos temáticos para cada uma das séries e construímos materiais para problematizar o passado e o presente a partir de questóes que permitem refletir historicamente sobre a realidade contemporânea. Compreende-se, portanto, que,

no ensino de História, problematizar é construir uma problemática acerca do passado, a partir de um objeto de estudo, tendo como referência o cotidiano e a realidade presente daqueles que vivem a História, bem como as questôes postas pelos historiadores. (Schimidt, 2002, p. 208)

A partir desta discussão de cidadania, propóem-se como objetivos do ensino de História:

- "valorizar o direito de cidadania dos indivíduos, dos grupos e dos povos como condição de efetivo fortalecimento da democracia, mantendo-se o respeito às diferenças e à luta contra as desigualdades" (Brasil, 1998a, p. 43);

- "conhecer e respeitar o modo de vida de diferentes grupos, em diversos tempos e espaços, em suas manifestaçóes culturais, econômicas, políticas e sociais, reconhecendo semelhanças e diferenças entre eles, continuidades e descontinuidades, conflitos e contradiçóes sociais" (Brasil, 1998a, p. 43);

- promover a reflexão e a análise da realidade social na qual o aluno está inserido, identificando e discutindo os problemas contemporâneos;

- auxiliar a distinção entre os diferentes grupos que compóem as sociedades ao longo da história, abordando a diversidade da experiência humana e a percepção das relações de poder, dos consensos e conflitos que se estabelecem entre os diferentes sujeitos sociais; 
- discutir a historicidade das experiências sociais de participação dos indivíduos e grupos sociais na construção coletiva da sociedade.

\section{O ENSINO DE HistóRIa COMO PRÁTICA DE LEITURA E ESCRITA}

Outro eixo da proposta pedagógica é a indissociabilidade entre o ensino de História e a prática da leitura e produção de textos. Discordando da ideia de que ensinar a ler e a escrever sejam atribuiçóes exclusivamente da disciplina de Português, defendemos que

Ler e escrever são tarefas da escola, questôes para todas as áreas, uma vez que são habilidades indispensáveis para a formação de um estudante, que é responsabilidade da escola. Ensinar é dar condiçóes ao aluno para que ele se aproprie do conhecimento historicamente construído e se insira nessa construção como produtor de conhecimento. Ensinar é ensinar a ler para que o aluno se torne capaz dessa apropriação, pois o conhecimento acumulado está escrito nos livros, revistas, jornais, relatórios, arquivos. Ensinar é ensinar a escrever porque a reflexão sobre a produção de conhecimento se expressa por escrito. (Guedes; Souza, 2004, p. 16)

Para efetivar essa concepção no ensino de História, propomos os seguintes objetivos:

- incentivar a leitura e a interpretação de diferentes gêneros de textos (literário, artigos de jornais e revistas, textos publicitários, científicos), relacionando-os com o contexto histórico em que foram produzidos;

- promover a leitura e a interpretação de um conjunto diversificado de documentos históricos e de mapas;

- estimular constantemente o aluno a expressar-se em diferentes linguagens: textos escritos de natureza diversa, apresentaçóes e discussōes orais, debates de assuntos polêmicos; desenhos; maquetes, entre outros exemplos.

\section{A AVALIAÇÃo PERMANENTE dos LIVROS Didáticos UTILIZAdos E A ELABORAÇÃO DE MATERIAIS DIDÁTICOS}

A Subárea de História desenvolveu uma sistemática de escolher os livros didáticos a partir de seminários que reúnem todos os professores 
e professoras e objetivam contribuir para a discussão da prática docente e da proposta da Subárea, relacionando-a com o nível de ensino a que se destina o Programa Nacional do Livro Didático (PNLD). Com isso, seja na escolha do livro didático para as séries iniciais do Ensino Fundamental ou para o Ensino Médio, a tarefa é compartilhada entre todos(as) os professores(as) da Subárea. A partir de uma ficha adaptada do modelo proposto pelo PNLD, cada professor(a) fica responsável pela análise de um determinado número de coleçóes previamente selecionadas a partir das resenhas do Guia do PNLD e, posteriormente, apresenta o resultado do seu trabalho para o grupo de professores que, após uma série de discussóes, escolhe a coleção cuja proposta teórico-metodológica mais se aproxima dos eixos da proposta de ensino da Subárea.

Desde o ano de 2000, nos anos iniciais do Ensino Fundamental, vem-se adotando a coleção Historiar: fazendo, contando e narrando a História, de autoria de Dora Schmidt, cujo projeto editorial passou por algumas modificaçóes, entre elas o nome da coleção, atualmente denominada Trocando Idéias: historiar. Essa coleção tem sido um importante suporte que auxilia o trabalho pedagógico.

Nesse período, nas séries finais do Ensino Fundamental, trabalhou-se, respectivamente, com três coleções de livros didáticos: coleçáo História Temática, dos autores Roberto Catelli Júnior, Andréa Montellato e Conceição Cabrini; História - Cotidiano e Mentalidades, de Ricardo Dreguer e Eliete Toledo e, dos mesmos autores, História: conceitos e procedimentos. No Ensino Médio, desde o início de 2004, adota-se o livro Oficina da História - História Integrada, de Flávio de Campos e Renan Garcia Miranda, cujo projeto passou por uma reformulação editorial e atualmente denomina-se $A$ Escrita da História, embora mantenha a mesma proposta pedagógica.

Acreditamos que a avaliação permanente dos livros didáticos escolhidos deve ser uma tarefa cotidiana. Tanto na preparaçáo das aulas quanto na prática pedagógica cotidiana, percebem-se os limites da adoção e utilização de determinada coleção. Além disso, considerando o pressuposto de que o conhecimento histórico deve estar relacionado com a experiência social do aluno e contribuir para a compreensão da realidade na qual estamos inseridos, sentimos necessidade de complementar ou modificar o livro didático e de produzir materiais didáticos, muitos deles relacionados com a história de Goiás. 


\section{Revista Solta a Voz, v. 20, n. 2}

\section{A INDISSOCIABILIDAdE ENTRE PRÁticA PEDAGógICA E PESQUISA}

Ao longo dos anos, a operacionalização da proposta pedagógica no planejamento e no cotidiano da sala de aula nos desafia a transformar nosso fazer pedagógico em objeto de pesquisa.

No processo de elaboração da proposta de ensino, ao discutirmos a pesquisa na Subárea de História, decidimos que não faríamos um projeto coletivo, envolvendo todos os docentes. Acreditamos que a escolha de um objeto de pesquisa é um processo muito particular, porque envolve a subjetividade do pesquisador, sua história de vida e sua trajetória acadêmica, além de ser uma maneira particular de vivenciar a prática docente. Porém, mais do que esses aspectos, o ato de dedicar-se à pesquisa envolve desejos, interesses, escolhas e ritmos diferentes de trabalho. Enfim, as diferentes trajetórias profissionais e pessoais encaminharam os docentes da Subárea para projetos individuais de pesquisa. Delineamos, assim, uma linha de pesquisa intitulada Ensino de História: pesquisa e prática pedagógica (Delgado, 2003).

Ao avaliarmos essas diretrizes, percebemos que nem todos os docentes desenvolveram projetos de pesquisa a partir das premissas da nossa linha de pesquisa. Ao longo desses anos, encontram-se registradas na Pró-Reitoria de Pesquisa e Pós-Graduação da UFG os seguintes projetos de pesquisa: Memória e literatura: a construção de experiências interdisciplinares, coordenado pela professora Andréa Ferreira Delgado, com a participação da professora Ilse Leone Borges Chaves de Oliveira, e África, afrodescendentes e o ensino de história, coordenado pela professora Maria do Carmo Tedesco, com a participação das professoras Andréa Ferreira Delgado e Cristina de Cássia Pereira Moraes. Infelizmente, os limites deste texto não permitem apresentar os produtos dessas pesquisas. Acreditamos, no entanto, que esses trabalhos (Delgado; Oliveira, 2004, 2006, 2008; Oliveira; Delgado, 2008a, 2008b; Tedesco, 2004, 2007a, 2007b) configuram itinerários para compreender a operacionalização dos eixos da proposta de ensino na prática cotidiana da sala de aula.

Discutimos, entâo, a possibilidade de mudar a estratégia e construirmos um projeto coletivo de pesquisa para a Subárea. Outro aspecto que colaborou para efetivarmos essa proposta foi a criação, em 2007, do Núcleo de Estudos e Pesquisas em Ensino de História (NESPEH), integrando os professores da Subárea de História, inicialmente com os profes- 
sores de Estágio do Departamento de História da UFG e posteriormente com outros professores e pesquisadores de ensino de História.

Para iniciar a pesquisa no NESPEH, decidimos elaborar um projeto para delinear várias linhas de pesquisa, com o objetivo de estimular e abrigar múltiplos projetos de pesquisa dos pesquisadores associados, sejam eles professores do Cepae ou de outras instituiçóes da UFG. O objetivo geral do projeto Saber escolar e conhecimento histórico: itinerários de configuração da história ensinada (Cepae, 2008, p. 18) é ambicioso:

Investigar o saber escolar, concebido como saber específico e com configuraçôes epistemológicas próprias, por meio da construção de projetos de pesquisa que promovam a inter-relação entre o conhecimento histórico acadêmico, o conhecimento produzido no campo do ensino de história e os saberes docentes construídos ao longo de nossa experiência como professores.

Para efetivá-lo, estabelecemos as seguintes linhas de pesquisa para a investigação do processo de construção de saberes históricos na escola e na sala de aula: 1) O campo do ensino de História: investigaçóes teóricas acerca do saber escolar e dos saberes docentes; 2) Incorporação da renovação historiográfica no ensino de História: diferentes caminhos e concepçôes teóricas; 3) Livros didáticos: política educacional, investigação da produção nacional e o uso em sala de aula; 4) Produção de materiais didáticos para a Educação Básica; 5) Procedimentos metodológicos de análise de documentos históricos em sala de aula; 6) A incorporação de diferentes linguagens no ensino de História: literatura, cinema, música, iconografia, cartografia, mídia; 7) Educação patrimonial: patrimônio e memória na Educação Básica.

Essas linhas de pesquisa representam nossa concepção da pesquisa como componente da prática pedagógica, visto que buscamos unir a reflexão teórica e metodológica aos desafios cotidianos suscitados pela efetivação da proposta de ensino de História até aqui esboçada.

Ao longo do artigo, procuramos entretecer concepçóes sobre história, educação e História escolar para delinear os itinerários de uma proposta de ensino de História construída no cotidiano da escola. Esperamos ter alcançado o objetivo de suscitar, a partir da nossa experiência, a discussão de um conjunto de questóes que instigam a produção dos pesquisadores e pesquisadoras do campo do ensino de História. 


\section{Revista Solta a Voz, v. 20, n. 2}

\section{REFERÊNCIAS}

BITTENCOURT, Circe M. Fernandes. Ensino de história: fundamentos e métodos. São Paulo: Cortez, 2004.

. Identidade nacional e ensino de história do Brasil. In: KARNAL, Leandro (org). História na sala de aula: conceitos, práticas e propostas. São Paulo: Contexto, 2003, p. 185-204.

. Propostas curriculares de história: continuidades e transformações. In: BARRETO, Elba S. de Sá (Org.). Os currículos do ensino fundamental para as escolas brasileiras. Campinas, São Paulo: Autores Associados/Fundação Carlos Chagas, 1998.

BRASIL. Ministério da Educação e Cultura. Secretaria de Educação Fundamental. Parâmetros Curriculares Nacionais: terceiro e quarto ciclos. História. Brasília, 1998a.

- Parâmetros Curriculares Nacionais: terceiro e quarto ciclos. Apresentação dos temas transversais. Brasília, 1998b.

CAIMI, Flávia Eloisa. Conversas e controvérsias: o ensino de história no Brasil (1980-1998). Passo Fundo, RS: UPF, 2001.

CARVALHO, José Murilo de. Cidadania no Brasil. O longo caminho. Rio de Janeiro: Civilização Brasileira, 2007.

CEPAE - Centro de Ensino e Pesquisa Aplicada à Educação da UFG. Projeto Político-Pedagógico. Goiânia: 2002 (atualizado em 2007).

CEPAE - Subárea de História. Projeto de ensino da disciplina História. Goiânia, 2004. (mimeo.)

. Subárea de História. Saber escolar e conhecimento histórico: itinerários de configuração da história ensinada. Goiânia, 2008.

CHERVEL, André. História das disciplinas escolares: reflexóes sobre um campo de pesquisa. Teoria \& Educação. Porto Alegre, n. 2, p. 177-229, 1990.

CHEVALLARD, Yves. La transposición didáctica. Del saber sabio al saber enseñado. Buenos Aires: Aique Grupo Editor, 2005. 
DELGADO, Andréa Ferreira. Ensino de História: pesquisa e prática pedagógica - A construção de uma linha de pesquisa para a Subárea de História. Trabalho apresentado no II Encontro de Pesquisadores do Cepae. Goiânia, 2003. (mimeo.)

DELGADO, Andréa Ferreira; OLIVEIRA, Ilse Leone B. C de. A alimentação como prática cultural: uma experiência interdisciplinar de ensino de história. Revista Solta a Voz, v. 15, n. 2, p. 95-107, jul-dez. 2004.

- Educação patrimonial como experiência interdisciplinar: patrimônio e memória na Cidade de Goiás. Revista Solta a Voz, v. 19, n. 2, p. 135-150, jul-dez. 2008.

- Memória e tessitura da narrativa: uma experiência escolar de leitura. Revista Solta a Voz, v. 17, n. 2, p. 119-133, jul-dez. 2006.

DUBY, Georges; LARDREAU, Guy. Diálogos sobre a Nova História. Lisboa: Publicações Dom Quixote, s.d.

FONSECA, Selva Guimarães. Caminhos da história ensinada. Campinas, São Paulo: Papirus, 2000.

- Didática e prática de ensino de história. Campinas, São Paulo: Papirus, 2003.

FORQUIN, Jean-Claude. Escola e cultura. As bases epistemológicas do conhecimento escolar. Porto Alegre: Artes Médicas, 1993.

GABRIEL, Carmen Teresa. O conceito de história-ensinada: entre a razão pedagógica e a razão histórica. Reflexões sobre a natureza epistemológica do saber histórico escolar. In: CANDAU, Vera Maria (org.). Reinventar a escola. Petrópolis, RJ: Vozes, 2000, p. 238-259.

GUEDES, Paulo; SOUZA, Jane. Leitura e escrita são tarefas da escola e não só do professor de português. In: NEVES, Conceição Neves (org.) Ler e escrever: compromisso de todas as áreas. Porto Alegre: Editora da UFRGS, 2004, p. 16-23.

JENKINS, Keith. A história repensada. São Paulo: Contexto, 2004.

LOPES, Alice Ribeiro Casimiro. Conhecimento escolar: inter-relaçóes com conhecimentos científicos e cotidianos. Contexto e Educação. Ijuí RS, no. 45, p. 40-59, jan./mar. 1997a. 
- Conhecimento escolar: processos de seleção cultural e de mediação didática. Educação \& Realidade. Porto Alegre, no. 22, p. 95-111, jan./ jun., 1997b.

MAGALHÁES, Marcelo de Souza. História e cidadania: por que ensinar história hoje? In: ABREU, Martha; SOIHET, Raquel (orgs.). Ensino de História: conceitos, temáticas e metodologias. Rio de Janeiro: Casa da Palavra, 2003, p. 168-184.

MIRANDA, Sônia. O que significa educar para a compreensão histórica? Um olhar a partir de um programa de avaliação educacional. História \& Ensino. Londrina, v. 9, p. 301-319, out. 2003.

MONTEIRO, Ana Maria Ferreira da Costa. Professores: entre saberes e práticas. Educação \& Sociedade, nº 74, p. 121-142, abr. 2001.

. A história ensinada: algumas configurações do saber escolar. História \& Ensino. Londrina, v. 9, p. 37-62, out. 2003.

. Ensino de História: entre saberes e práticas. In: ARIAS NETO, José Miguel (org.). Dez anos de pesquisas em Ensino de História. Londrina, PR: AtritoArt, 2005a, p. 757-766.

. A história ensinada: saber escolar e saberes docentes em narrativas da história escolar. Anais Eletrônico Suplementar do XXIII Simpósio Nacional de História. Associação Nacional de História - ANPUH. Londrina, PR, 2005b.

- Professores de História: entre saberes e práticas. Rio de Janeiro: Mauad X, 2007.

MOREIRA, Antonio Flavio Barbosa; SILVA, Tomaz Tadeu da. Sociologia e teoria crítica do currículo: uma introdução. In: MOREIRA, Antonio F. Barbosa; SILVA, Tomaz Tadeu da (orgs.). Currículo, cultura e sociedade. São Paulo: Cortez, 1995, p. 7-37.

MOREIRA, Antonio Flavio Barbosa. Currículo, utopia e pós-modernidade. In: MOREIRA, Antonio F. Barbosa (org.). Currículo: questôes atuais. Campinas, SP: Papirus, 2003, p. 9-28.

OLIVEIRA, Ilse Leone B. C de; DELGADO, Andréa Ferreira. Imaginação histórica: ficção e subjetividade na escrita escolar. Gragoatá. Niterói: EdUFF, n. 25, p. 95-118, $2^{\circ}$ sem. 2008b. 
. O entrelaçamento de literatura e memória em experiências interdisciplinares de ensino de Português e História. Revista Solta a Voz, v. 19, n. 1, p. 45-61, jan/jun. 2008a.

SCHIMIDT, Maria Auxiliadora. História. In: KUENZER, Acacia (org.). Ensino Médio - construindo uma proposta para os que vivem do trabalho. São Paulo: Cortez, 2002.

SCHIMIDT, Maria Auxiliadora; CAINELLI, Marlene. Ensinar história. São Paulo: Scipione: 2004.

TEDESCO, M. C. F. A história da África no currículo escolar. Revista Solta a Voz, Goiânia, v. 15, n.2, p. 133-143, 2004.

. Povos Africanos Antes da Chegada do Europeu. In: SILVA, Marilena; GOMES, Uene José (Orgs.). África, Afrodescendência e Educação. Goiânia: Editora UCG, 2007a, p. 23-37.

. Histórias que se entrelaçam. Sociedade dos Prazos: uma experiência européia na África. Revista Brasileira do Caribe, Goiânia, 2007b. Vol. VII no. 14, jan./jun. 2007b.

VEYNE, Paul. Como se escreve a história. Lisboa: Edições 70, 1983.

Recebido em: 30 jul. 2009 Aceito em: 05 nov. 2009 